\title{
Locating intra city bus terminals using fuzzy logic with emphasis on city development and community alliance: case study of Tasuj
}

\author{
N. Marsousi \& K. Pourebrahim \\ Department of Geography and City Planning, Payam Noor University, \\ Tehran Campus, Iran
}

\begin{abstract}
This paper is written with the objective to present an approach for site search for an intra city bus terminal, which is considered as a public service provided by the city establishment.

City expansion requires careful planning. It should take place when there is controlled interaction among different factors that make up a city such as population, society, economy, etc. If a city expands without planning or without paying attention to its special factors, then it can produce undesirable social and environmental conditions resulting in prejudicial consequences.

In site searches for public services, such as bus terminals, one should consider the inherent factors of city, population chrematistics of city communities, and city districts with the intention of creating greater harmony and alliance among city communities.

Tasuj is a small city in the Shabestar metropolitan area in West Azerbaijan Province. Tasuj was used as a case study for applying the approach outlined in this paper with the consideration given to City expansion and increased alliance among City communities. Different communities were identified in Tasuj for this study. Population density was calculated for these communities using Köln law (for electrified metal objects). We, then, performed buffering by using population density in a GIS environment and selected common areas by applying an overlay intersect function. We, finally, arrived at the best area, which could satisfy all communities. We selected the best location by applying the fuzzification method, taking into account city expansion course and alliance
\end{abstract}


among city communities. Other factors play a role in site selection for an intra city bus terminals, but this paper focuses on the two already mentioned.

Keywords: community alliance, skeletal development, GIS, fuzzy logic, site selection.

\section{Introduction}

The criterion for action or judgement is the guideline for planning [2]. Ethnical and local prejudices in majority of small cities are the basis for actions and judgments. City planners should resolve these issues from a socio-cognitive point of view as they root in the social setting of a community.

Sociology is based on codes of the real world and social living [3]. Life experiences are interrelated and widely interact with each other. Prejudices in city communities are one of sociological issues that are influenced by interaction of behaviors exerted by society members in attempts to fulfill their basic needs and personal objectives.

Members of society are all interested in having easy and rapid access to available services. They may even compete with each other for those services. These social actions and reactions are evident in locating interacity bus terminals as it is considered a service location.

Considering that proximity and accessibility are required for social integration [15], social groups enter into competition with each other to have proximity and accessibility to services in order to fulfill their needs and expectations. Therefore, the group that exerts more power can expect to enjoy more services.

City management normally attempts to harmonize system with the interaction of various making components of city establishment in an attempt to fulfill its objective to provide better services to the community [6]. However, what they should do initially is to harmonize the element first and next work on the subelements. In other words, they should initially unite city population and next work on other elements (proximity and accessibility).

An important issue to be considered in locating an intra city bus terminal is the physical expansion of city. This issue can be linked to the first one because any city community that can command more services, which should bring about greater employment opportunities, should expect faster development compared to other communities. City management policies also have a determining role in the decision making.

Two other important factors influence physical expansion of a city. One is the development potential of a community which comes from its ecological conditions, outlook, culture, and the like. These factors can consolidate city development in a certain community. The other factor is development accelerators, which could be social, economical, and political. Development accelerators could be so powerful that would drive community potential.

Intra city bus terminals are types of city services that could act as development accelerators. Wherever intra city bus terminals are located, those communities could experience economic expansion. This reason together with 
air pollution caused by intra city bus terminals forces city planners to propose a location that would not stand in the way of city expansion.

Considering all these issues, we now discuss an approach for locating intra city bus terminals.

\section{Theoretical aspects}

\subsection{Site search}

Site search is a step towards fulfilling the needs of those who would benefit from using the site for its intended purposes. Criteria used for site search fall into supply and demand groupings [8]. Site search means informed and volitional intervention in relationships among people, activities and spaces with the intention to create harmony [4].

The intended objective for the site search usually has the highest influence on nominating locations for facilities [1]. In methods used for site search, such as pmedian and p-center, the location is selected in such a way that the distance and the time required to have access to the facilities are minimized [18].

The dynamic nature of demand for using facilities over time is another consideration for site search. Based on the space requirements and demand for using given facilities, both of which change continuously, several locations are unusually nominated with the consideration given to the date set out for commencement [17].

Scholars believe that the ultimate criterion for site selection is cost. Therefore, cost is used as the base for selection of the best location out of all nominated for the intended purpose [9]. It is possible to emphasize that aerial proximity has special bearing in site search with the location type and all other pertaining conditions to come next. This can become a source of quarrel between city communities, especially in small cities.

An important characteristic feature of a dynamic and sound economy is the way it distributes its resources and development benefits among a majority of the population [14]. Space planners should resort to site search techniques in order to help achieving this objective, a practice that is not currently exercised.

\subsection{Population density}

According to Köln's law, electric charge always distribute over external surface of an electrified metal objects. The surface density of an object is the electric charge per unit area of the object. If there is surface density, then, it can be calculated from the equation, where $\mathrm{q}$ is electric charge and $\mathrm{A}$ is the surface area [16].

$$
\delta=\frac{q}{a}
$$

If sigma is population density, A is surface area, and q is number of people in the area, population density can be calculated by the same formula. Halderen has used the inverse equation in calculation of awkward city growth. In Halderen 
model, net per capita is equal to surface area divided by the number of population [5].

In this paper, we use population density to study communities. The purpose of using this model is to calculate aerial proximity of bus terminal to every individual person living in the city. Every person living in the city has the same weight in this calculation.

\subsection{Fuzzy logic}

This theorem was introduced for conditions of uncertainty by Professor Asgar Lotify Zadeh, at Berkley University [11]. This theorem can mathematically order many inexact concepts, variables, and systems to provide a base for analysis, control and decision making in uncertainties [12].

Study Chart:

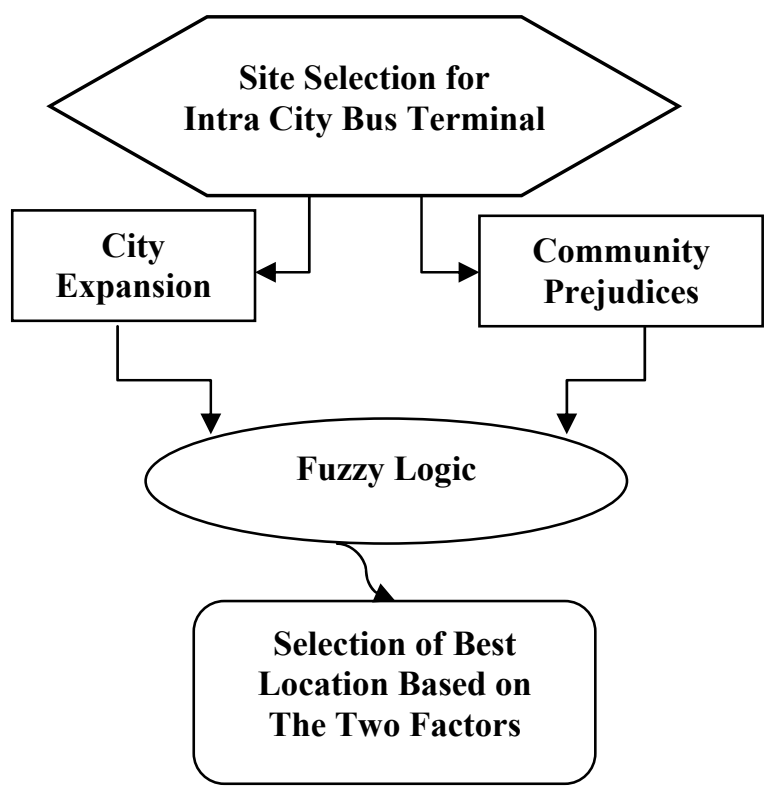

$$
\begin{aligned}
& - \text { Exploring City Communities } \\
& - \text { Population Density Calculation } \\
& \text { - Buffering Based on Population Density (1) } \\
& - \text { Using Common Intersection Function (2) } \\
& - \text { Selecting Best Location in Terms of Proximity } \\
& -\begin{array}{l}
\text { Pelecting Best Location in Terms of Aerial } \\
\text { Proximity and community Prejudices }
\end{array} \\
& \text { WIT Transactions on Ecology and the Environment, Vol 142, (c) } 2010 \text { wit Press }
\end{aligned}
$$




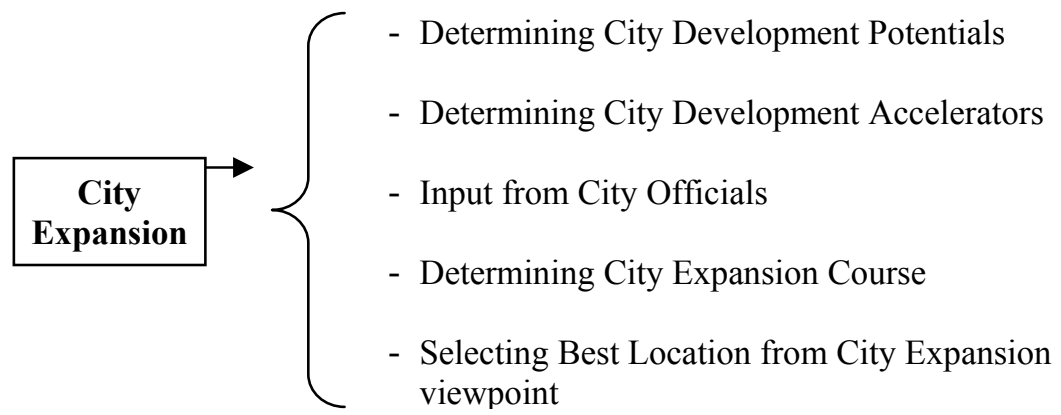

Fuzzy logic can be applied to various sciences by following the steps discussed below [13].

A. Fuzzification: defining fuzzy sets for input and output variables

B. Inference: developing fuzzy rules to include ifs and buts as well as the research criteria

C. Difuzzification: assigning numerical values to data by using different approaches

Applying these steps to GIS is given as an example. We first create district map for vector layers. Then, we reclassify the resulting map. Next, we assign numerical values zero and one, or fractions between zero and one to ifs and buts. In the final step, we use suitable function and select a location for the project [10].

\section{Basic information about the city used for case study}

Tasuj is a city in Shabestar township of West Azerbaijan Province in Iran. It is also the center of Anzab District. Tasuj had a population of 7332 persons and was rated as $29^{\text {th }}$ city of West Azerbaijan Province and forth city in Shabestar township according to the latest census taken in 2006.

Tasuj is located 21 kilometers west of Shabestar center, 87 kilometers west of Tabriz, and 721 kilometers from Tehran. Tasuj is located at 38:19 degrees

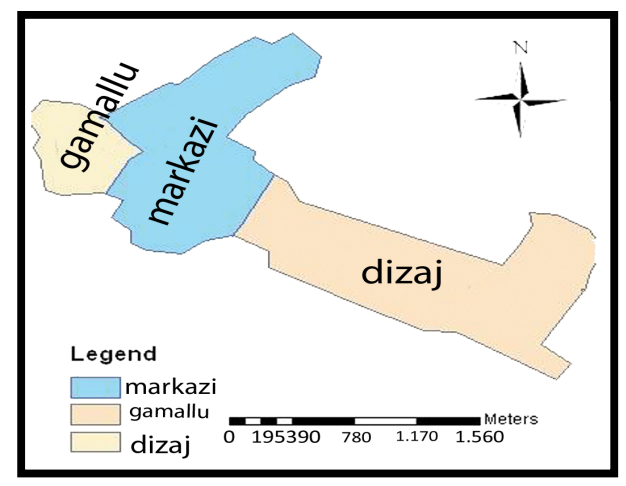

Figure 1: Tasuj City Communities. 
latitude and 45:21 degrees longitude [7].The city has three large communities according to our survey. One is Dyzej Sheikh Marjan Community, which was a village earlier and became a part of the city when city expanded. The other two communities are the Central Community and Jamalou Community.

\section{Site selection}

The population density for these three communities are calculated and stated in Table 1 based on the area and population of each community.

Considering that proposed population densities are for community alliance and solving neighborly problems, we substitute every two densities for buffering.

After careful analysis of population densities, the best area from a neighborly point of view of all communities was determined and is marked by hatched lines in figure 2. As buffering is made with the objective to reach aerial proximity, therefore, every two population densities should be interchanged.

Table 1: $\quad$ Characteristics of community.

\begin{tabular}{|l|l|l|l|}
\hline Community Name & Jamalou & Central & $\begin{array}{l}\text { Dyzej Sheikh } \\
\text { Marjan }\end{array}$ \\
\hline Population (person) & 1331 & 3000 & 3000 \\
\hline Area (square meters) & 346509 & 1227036 & 1518230 \\
\hline Population Density & 0.0038 & 0.0024 & 0.0019 \\
\hline
\end{tabular}

Source: Tasuj Municipality.

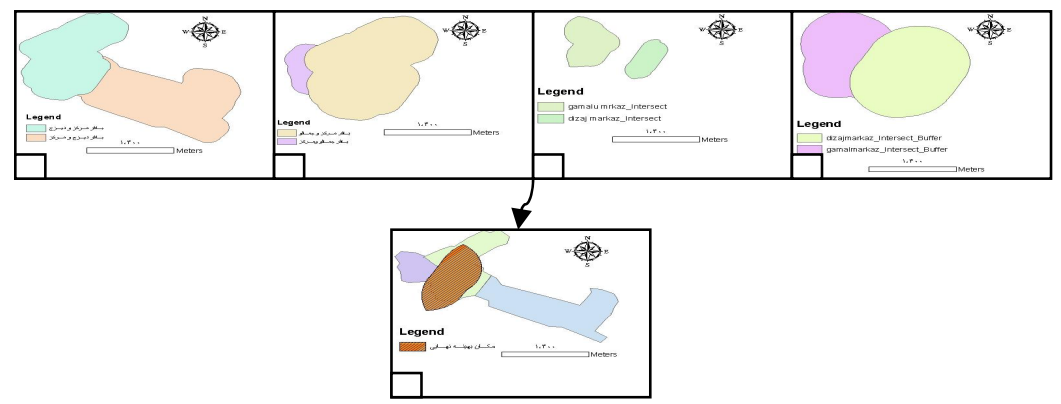

Figure 2: Approach for determining the best location from the viewpoints of proximity to all communities and solidifying community alliance.

Thus, every two communities are compared in calculations based on their population densities. The intersection area between two communities is selected. Finally, we do buffering for the two resulting sets and select their common area as the best location. 
Comfort, convenience, and easy access to services are factors that face prejudice in small cities and, therefore, are considered without planning or careful site location.

The course of city expansion is determined in above maps by looking at accelerating factors such as road constructions, city service provision, gas stations, and residential buildings. This was in agreement with what city officials had determined for the course of city expansions. The development potentials such as ecological and environmental conditions also fell within the course of city expansion in the area.

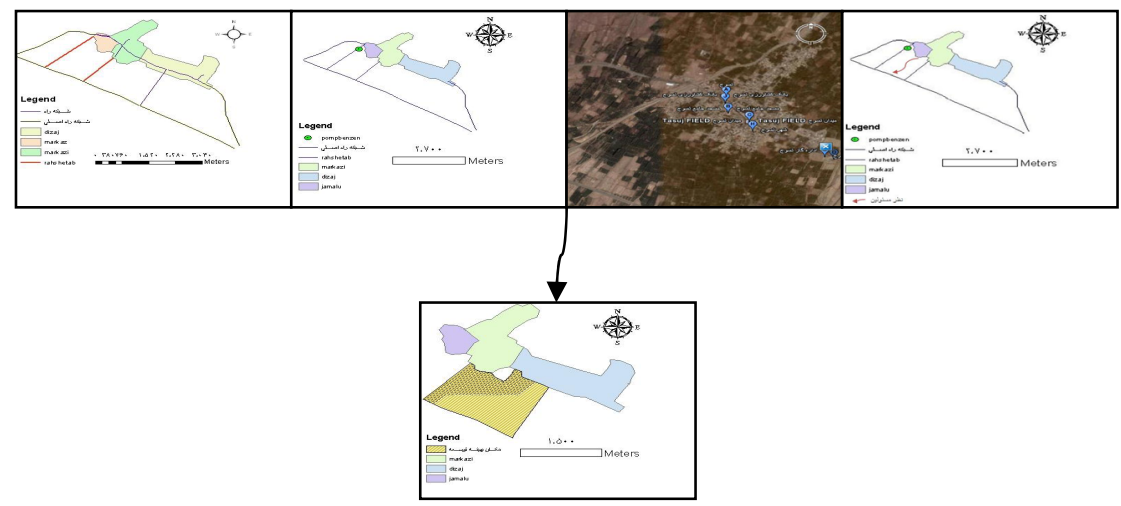

Figure 3: Determining city expansion course and selecting the best location from the viewpoint of city development.

An area was finally selected for construction of intra city bus terminal, which was not in the way of city expansion. Hatched lines on the maps mark this area. Two locations in the area are selected for the bus terminal. The final location to be selected from the nominated areas should not be in the way of city expansion and should have close proximity to all city communities.

We use fuzzy logic in the selection of the best location. We performed dataset combination after assigning values to the district areas. We first draw boundary maps for vector layers. We then fuzzyfied resulting polygons and selected the best location by assigning density to each layer. Both criteria had the same weight in this study.

Fuzzy weights applied in the second step of graph no 4 are stated in table 2.

Table 2: Weighing index assigned to each criteria.

\begin{tabular}{|c|c|c|c|c|c|}
\hline No & Type & Weigh & Zero & $\begin{array}{c}\text { Between Zero } \\
\text { and One }\end{array}$ & One \\
\hline 1 & $\begin{array}{l}\text { Best Area for } \\
\text { City Expansion }\end{array}$ & 1 & $\begin{array}{c}\text { Outer } \\
\text { Area }\end{array}$ & $\begin{array}{c}\text { Center-Outside } \\
\text { Border line }\end{array}$ & $\begin{array}{c}\text { Center of } \\
\text { best location }\end{array}$ \\
\hline 2 & Local Prejudice & 1 & $\begin{array}{c}\text { Outer } \\
\text { Area }\end{array}$ & $\begin{array}{c}\text { Center-Outside } \\
\text { Border line }\end{array}$ & $\begin{array}{c}\text { Center of } \\
\text { best location }\end{array}$ \\
\hline
\end{tabular}




\section{Conclusions}

Based on the final map, which was drawn by adding fuzzy values of different points, a location with highest fuzzy value was proposed as a suitable site for construction of intra city bus terminal in Tasuj.

Population make up of Tasuj is such that local prejudices for establishing service centers are highest. Furthermore, every community competes with others for closer proximity to service center.

Dyzej Sheikh Marjan community, which was a village in the past and later became a part of City, has become a source of deep social conflict for other communities.

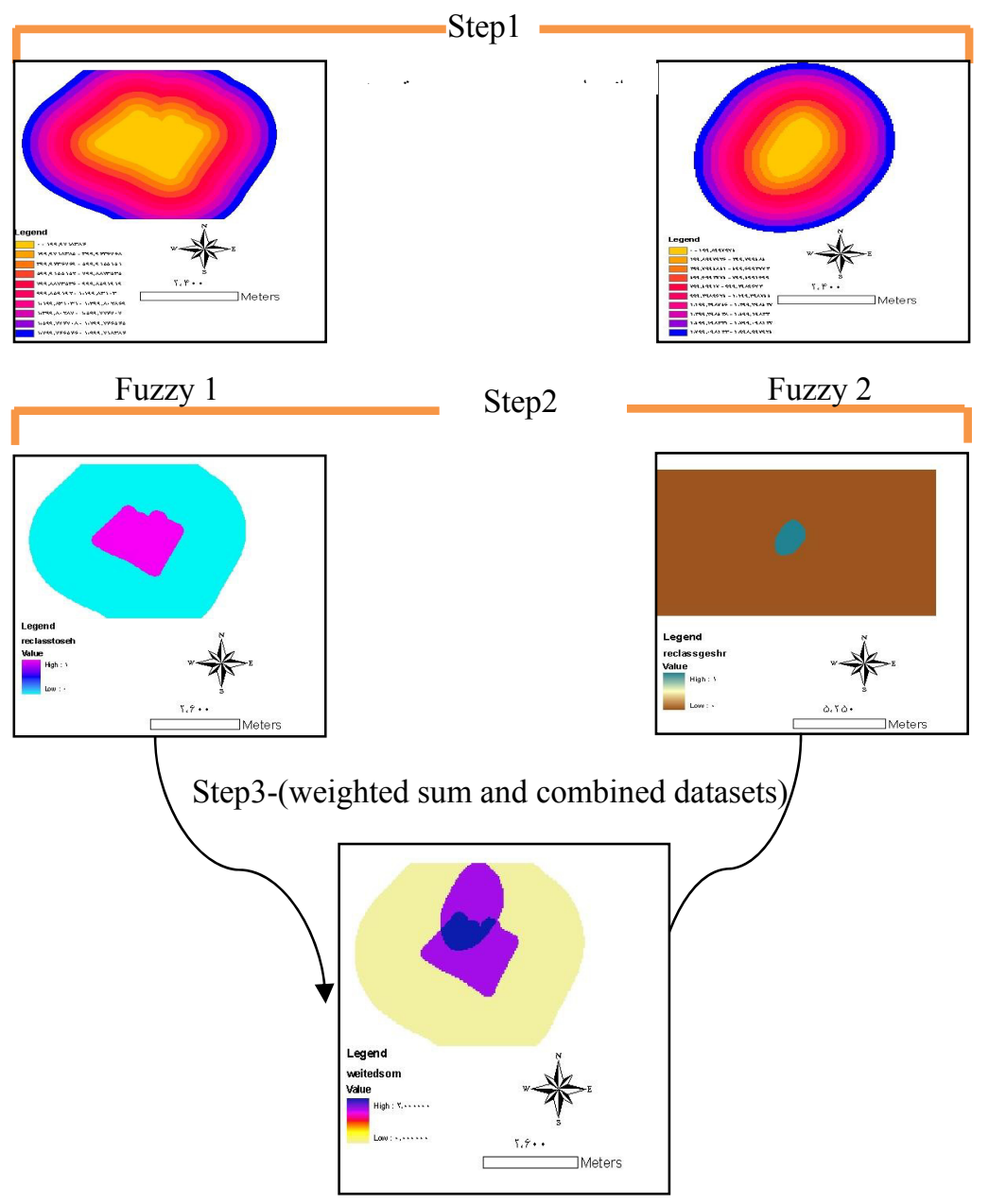

Figure 4: $\quad$ Steps in applying fuzzy logic to weighted indicators. 
Population density was proposed in this paper as an approach for preventing division among city communities. This approach is a suitable way for site selection of city service center including intra-city bus terminals in small cities.

Many factors should be considered for selection of intra-city bus terminal. Social unification and course of skeletal expansion in the city were discussed in this paper.

As social prejudice and availability of services result in community development, the course of city development is an indication of availability of better services in the same domain.

Services are development accelerator. Ecological and natural environment are development potential. Determining the course of city expansion and its opposite course in Tasuj was proposed as criteria for selecting the best location for intracity bus terminal.

With the help of GIS software and by using fuzzy approach, a suitable location can be selected by combining the best two available locations. The final objective of this paper was to propose an approach for appropriate site selection for general service provision, while preventing community division, which happens more often in small cities, creating social alliance and controlling skeletal expansion in city.

\section{References}

[1] Afandizadeh, S., Afyoonian, M.R., \& Jalal Barsari, A., Site Location for New Intra City Bus Terminals with the Objective to Reduce Access Time for Users, Comprehensive Traffic and Transport Studies in Tehran, 2007.

[2] Poor Mohammadi, M.R., City Land Usage Planning, Samt Publishing, 4th Edition, p. 105, 2008.

[3] Torab, A. A., Philosophy of Sciences. Chehr Publishing, p. 193, 1969.

[4] Habibi, S. H., Proceedings of conference on administration of sparse rural areas, Islamic Revolution Housing Foundation: Tehran, p. 19, 1997.

[5] Hekmat Nia, H. \& Moosavi, M. N., Application of Modeling in Geography with Emphasis on City and Regional Planning. Elm Novin Publishing: 1St Edition, p. 131, 2007.

[6] Razavian, M. T., City Civil Management. Paivand Noe Publishing, 1St Ed., p. 21, 2003.

[7] Office of Planning and Administration, East Azerbaijan Province, 2007.

[8] Sadi Mesgari, M. \& Mehdi Pour, F., Sit Search for University Dormitories using GIS. 2007.

[9] Saeedian Tabasi, M. \& Ahmadi Azar, K., Application of GIS in Parking Management and Site Search, 2006.

[10] Sanjari, S., ARC GIS9.2. Abed Publishing, 3rd Edition, p. 220, 2008.

[11] Farhoodi, R. \& Habibi, K., Site Search for City Land Fill Using Fuzzy Logic in GIS Environment (Case Study of Sanandaj), Journal of Fine Arts, No. 23, p. 16, 2006. 
[12] Koohsari, M. J. \& Habibi, K., Combining AHP Model and IO Logic in GIS Enviroment for Site Search for New City Amenties (Case Study: Site Search for a new Cemetery in Sanadaj), 2007.

[13] Mokhtari, M. \& Mary, M., Applications of SIMULINK and MATLAB in Engineering. Translated by Samadi Bokharaiee, V., Khorasan Publishing, 1st Edition, p. 103, 2002.

[14] Mahdavi, M. \& Karim Zadeh, H., Planimetry in Central District of Varzaghan Township for Locating Suitable Sites for Centers Providing Services to Rural Area Using GIS, Journal of Geographical Research, No. 55, p. 227, 2007.

[15] Mazini, M., City and Civil Engineering Papers. Tehran University Publishing, p. 94, 2007.

[16] Haliday, D., Reznik, R. \& Walker, J., Electricity and Magnetic, Fundamentals of Physics. Translated by Golestanian, N. \& Bahar, M., Mobtakeran Publishing, 3rd Edition, 2006.

[17] William A., A Facility Location Model Trading off Maximal Covering Objectives in a Clanging Network. Department of Systems and Information Engineering, 2006.

[18] Hongzhong J., A modeling Framework for Facility Location of Medical Services for Large Scale Emergencies. Epstein Department of Industrial and System Engineering, Unviersity of Southern California, 2005. 